\title{
Static and Dynamic Transmissin Error in Spur Gears
}

\author{
Evgeny Podzharov*, Vladimir Syromyatnikov, Julia Patricia Ponce Navarro and Ricardo Ponce \\ Navarro
}

University of Guadalajara, Electromechanical Engineering Department, Av. Revolución 1500, Guadalajara, Jalisco, México, C.P. 44430

\begin{abstract}
In high precision and heavily loaded spur gears the effect of gear errors is negligible, so the periodic variation of tooth stiffness is the principal cause of noise and vibration. High contact ratio spur gears could be used to exclude or reduce the variation of tooth stiffness. The analysis of static and dynamic transmission error of spur gears cut with standard tools of $20^{\circ}$ profile angle is presented in this paper. A simple method to design spur gears with a contact ratio nearly 2.0 is used. It consists of increasing the number of teeth on mating gears and simultaneously introducing negative profile shift in order to provide the same center distance. Computer programs to calculate static and dynamic transmission error of gears under load have been developed. The analysis of gears using these programs showed that gears with high contact ratio have much less static and dynamic transmission error than standard gears.
\end{abstract}

Key Words: Gear engagement model, high contact ratio gears, static and dynamic transmission model, low noise and vibration.

\section{INTRODUCTION}

As it is well known, the periodic change of tooth stiffness, gear errors, and friction force impulse at the pitch point are the principal causes of vibration and noise of gears. In high precision and heavily loaded gears, the effect of gear errors is insignificant, so the periodic variation of tooth stiffness and friction impulse noise are the most significant causes of noise and vibration.

High contact ratio spur gears could be used to exclude or reduce the variation of tooth stiffness. Kasuba [1] established experimentally that the dynamic loads decrease with increasing contact ratio in spur gearing. Sato, Umezawa, and Ishikawa [2] demonstrated experimentally that the minimum dynamic factor corresponds to gears with a contact ratio slightly less than 2.0 (1.95). The same result was found experimentally by Kahraman and Blankenship [3] and theoretically by Lin, Wang, Oswald, and Coy [4].

The increase in contact ratio can be implemented in two ways: 1) by decreasing pressure angle and 2) by increasing tooth height. Obviously, the use of a standard pressure angle and standard tools is preferable. In the author certificate (Nikolayev and Podzharov) [5] a simple method of design of high contact ratio spur gears with standard basic rack of $20^{\circ}$ profile angle was presented. This method allows us to design gears with a contact ratio nearly 1.95 . Vulgakov [6] proposed a method of design of nonstandard gears in generalized parameters and found that spur gears with a contact ratio of more than 2 and a pressure angle more than $20^{\circ}$ worked considerably quieter. Rouverol and Watanabe $[7,8]$ proposed maximum-conjugacy gearing which has a low pressure angle at pitch point and which increases slowly at the tip and at the root. The measurements also show a con-

*Address correspondence to this author at the University of Guadalajara, Electromechanical Engineering Department, Av. Revolución 1500, Guadalajara, Jalisco, México, C.P. 44430; Tel: 52-333-629;

E-mail: epodzhar@up.edu.mx siderable reduction in the noise level compared with standard gears.

In this paper a comparative analysis of static and dynamic transmission error in standard gears with $20^{\circ}$ pressure angle and high contact ratio gears also with standard basic rack of $20^{\circ}$ profile angle is given.

\section{DETERMINATION OF STATIC TRANSMISSION ERROR IN SPUR GEARS}

Let us study a tooth engagement model represented in Fig. (1a) to find the influence of load distribution between teeth on effective gear errors. Following Yelle and Burns [9] and Remmers [10] the tooth profile is represented as a slide (Fig. 1a) and the teeth as springs with rollers. The pitch error is modeled as a step base for spring; profile error and base pitch error as an undulated inclined slide surface.

Here, $C_{3 i}$ - stiffness of $i$-th pair of teeth,

$S_{i}$ - Kinematic error of $i$-th pair, composed by base pitch error and profile error,

$f_{\text {ptri }}$ - circular pitch error difference of $i$-th pair of teeth,

$x_{3}$ - static transmission error under load,

$f_{i r i}^{\prime}$ - local cinematic error of $i$-th pair of teeth,

$p_{b}$ - base pitch,

$\varepsilon_{\alpha}$ - transverse contact ratio.

A positive error corresponds to spring compressions which represent teeth. With these definitions the tooth deflection, which appears as the result of the action of positive tooth error is also positive. Then the transmission error $x_{3}$ can be expressed by current errors of several pairs of teeth, and its deflections $x_{3 i}$, in the following way:

$x_{3 i}=x_{3}+f_{i r i}^{\prime}$, 


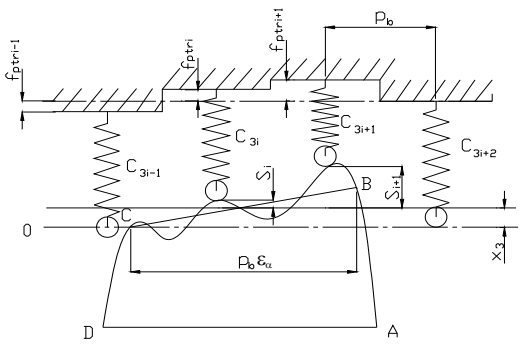

(a)

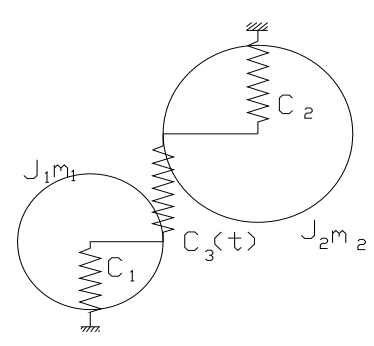

(b)

Fig. (1). Gear dynamic model: (a) model of tooth engagement, (b) dynamic model

where

$f_{i r i}^{\prime}=S_{i}+f_{p t r i}$.

The kinematic error during tooth edge contact at the beginning and at the end of tooth mesh (the sections $\mathrm{AB}$ and $\mathrm{CD}$ on the slide, see Fig. (1a) can be evaluated using the method exposed by Seireg and Houser [11] or can be described approximately as parabolas. The error in section BC of the slide can be represented as a sum of cosine and linear functions.

The normal force between teeth is equal

$F_{n}=\sum_{i=1}^{n} C_{3 i} x_{3 i}=\sum_{i=1}^{n} C_{3 i}\left(x_{3}+f_{i r i}^{\prime}\right)$

Transforming (3), we have:

$x_{3}=\left(F_{n}-\sum_{i=1}^{n} C_{3 i} f_{i r i}^{\prime}\right) / \sum_{i=1}^{n} C_{3 i}$

Using formulas (1) - (4), one can find the cinematic error of tooth engagement $x_{3}$ under load at any moment of time, which is static transmission error. At first the calculation is done with $\mathrm{n}=1$, assuming that $f_{i r 1}^{\prime}=f_{i r \max }^{\prime}$ is the maximum tooth error in the tooth engagement. Then, if $x_{3}+f_{i r 2}^{\prime}>0$, we accept $\mathrm{n}=2$ and continue the calculation, etc.

The method developed by Weber and Bonaschek [12] has been used to determine the tooth stiffness at any position.

\section{ANALYSIS OF STATIC TRANSMISSION ERROR OF STANDARD AND HIGH CONTACT RATIO SPUR GEARS}

The geometric parameters of gears analyzed here are shown in Table $\mathbf{1 .}$

The increase of contact ratio was carried out in the standard transmission by incrementing the sum of the number of teeth in the transmission by two and the simultaneous introduction of negative displacement of the gear tooth profile, so that the center distance remained the same.

The results of the calculations of static transmission error for the gears with parameters shown in Table $\mathbf{1}$ are presented in Fig. (2). In the graphics of Fig. (2), the values of transmission error are expressed in dimensionless form: $x_{3}^{*}=x_{3} / x_{3 O}$, where: $x_{3 O}=F_{n} / C_{3 O}$ : tooth deflection, $C_{30}$ : tooth stiffness of gear mesh.

It can be seen from the figure that the variation of standard gears (without errors) has a stepped form (curve 1). The stepped form of transmission error is due to change of tooth stiffness between one pair tooth contact zone and two pairs tooth contact zone. The static transmission error of this form can excite high level vibration.

The gear pair with high contact ratio and standard tooth height (2) has an increased tooth contact ratio $\left(\varepsilon_{\alpha}=1.93\right)$. This contact ratio was obtained by increasing the number of teeth on the pinion and the gear by one and introducing a negative profile tooth shift $\left(x_{1}=-0.393\right.$ y $\left.x_{2}=-0.52\right)$ according to the method proposed in [5]. The static transmission error here is not large but it has a peak that can be a

Table 1. Geometric Parameters of Gears

\begin{tabular}{|c|c|c|c|c|c|c|c|c|}
\hline No. & $\mathbf{m}, \mathbf{m m}$ & $\begin{array}{c}a_{W}, \\
\mathbf{m m}\end{array}$ & $z_{1}$ & $z_{2}$ & $\alpha_{t W}$ & $x_{1}$ & $x_{2}$ \\
\hline \hline 1 & 3.0 & 135 & 40 & 52 & $20^{\circ}$ & 0.00 & 0.00 \\
\hline 2 & 3.0 & 135 & 41 & 53 & $16.24^{\circ}$ & -0.39 & -0.52 & 1.000 \\
\hline 3 & 3.0 & 135 & 41 & 53 & $16.24^{\circ}$ & -0.39 & -0.52 \\
\hline
\end{tabular}

Here $m$ : module of gears, $a_{W}$ : center distance, $z_{1(2)}$ : tooth number of pinion (gear), $\alpha_{t W}$ : pressure angle, $x_{1(2)}$ : shift coefficients of pinion (gear),

$h_{a}^{*}:$ addendum coefficient. 


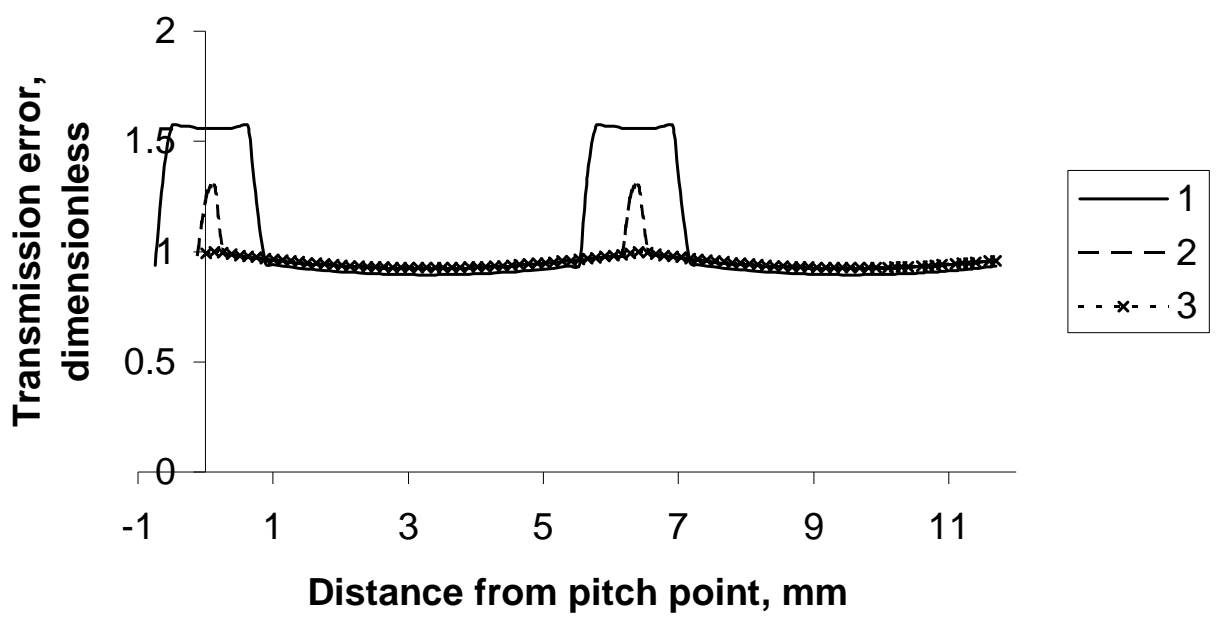

Fig. (2). Static transmission error in gears: 1-standard gear, 2-high contact ratio gear with standard tooth height, 3-high contact ratio gear with increased tooth height.

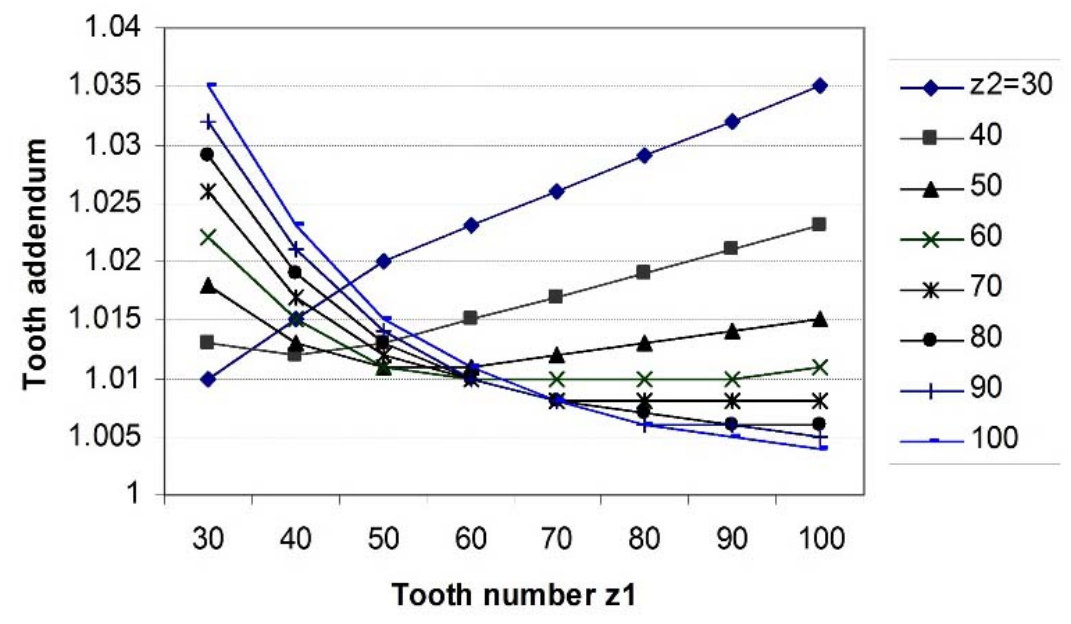

Fig. (3). Tooth addendum coefficient corresponding to contact ratio of 1.96.

cause of vibration excitation. To further reduce the transmission error, we must slightly increase tooth addendum by 0.018 of its value ( $h_{a}^{*}=1.018$ ). The contact ratio of this gear is 1.96. In this case the static transmission error almost completely disappears (curve 3 in Fig. 2). Tooth addendum coefficients calculated for contact ratio 1.96 are presented in Fig. (3) for tooth numbers from 30 to 100 . The necessary increment of tooth addendum to get contact ratio 1.96 is not large except for low numbers of teeth.

\section{DYNAMIC TRANSMISSION ERROR}

The dynamic model of a pair of gears is presented in Fig. (1b). Here, $C_{1(2)}$ : stiffness of support of pinion (gear), $C_{3}(t)$ : stiffness of tooth mesh, $m_{1(2)}$ : mass of pinion (gear), $J_{1(2)}$ : moment of inertia of pinion (gear). These parameters have the following values $C_{1}=45.5 \mathrm{MN} / \mathrm{m}, C_{2}=$ $81 \mathrm{MN} / \mathrm{m}, C_{30}=36.3 \mathrm{MN} / \mathrm{m}, m_{1}=3.38 \mathrm{~kg}, m_{2}=4.5 \mathrm{~kg}$, $J_{1}=0.297 \cdot 10^{-3} \mathrm{~kg} \mathrm{~m}^{2}, J_{2}=0.835 \cdot 10^{-3} \mathrm{~kg} \mathrm{~m}^{2}$. The dissipa- tive coefficient was expected to be $\xi_{i}=0.05$. In this dynamic model the tooth engagement is represented by a periodic structure shown in Fig. (1a). The whole dynamic model is described by three differential equations with periodic functions that were solved by a program based on the RungeKutta method.

$$
\begin{gathered}
\mu\left(\ddot{x}_{3}+\ddot{x}_{1}+\ddot{x}_{2}\right)+F_{\delta}(\varphi)+F_{c}(\varphi)=F_{n 0}, \\
m_{1} \ddot{x}_{1}+R_{1} \dot{x}+C_{1} x_{1}=F_{\delta}(\varphi)+F_{c}(\varphi), \\
m_{2} \ddot{x}_{2}+R_{2} \dot{x}_{2}+C_{2} x_{2}=F_{\delta}(\varphi)+F_{c}(\varphi), \\
F_{\delta}(\varphi)=\sum_{i=1}^{n} R_{3 i} \dot{x}_{3 i}, \\
F_{c}(\varphi)=\sum_{i=1}^{n} C_{3 i} x_{3 i},
\end{gathered}
$$

(when $x_{3 i} \leq 0 \quad R_{3 i}=0$ and $\mathrm{C}_{3 \mathrm{i}}=0$ ) 

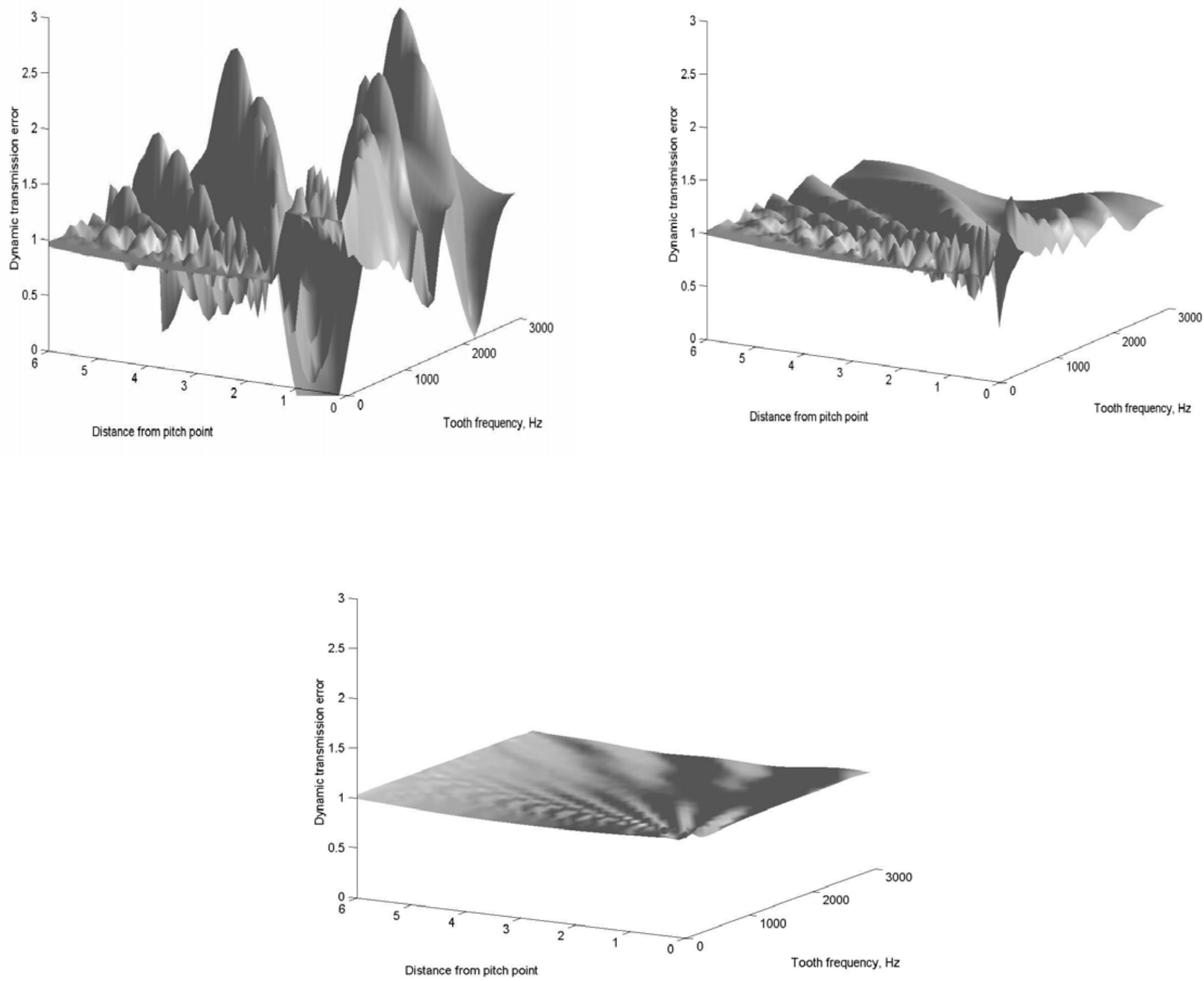

Fig. (4). Dynamic transmission error: (a) Standard gear, (b) High contact ratio gear with standard tooth height, (c) High contact ratio gear with increased tooth height.

where

$\mu=\mu_{1} \mu_{2} /\left(\mu_{1}+\mu_{2}\right)$ : effective mass of a pair of gears;

$\mu_{1}=J_{1} / r_{b 1}^{2}$ : effective mass of pinion;

$\mu_{2}=J_{2} / r_{b 2}^{2}$ : effective mass of gear;

$R_{1(2)}=2 \xi_{1(2)} \omega m_{1(2)}$ : damping coefficients in the support

of pinion (gear);

$R_{3 i}=2 \xi_{3} \omega \mu$ : damping coefficient in $i$-th pair of teeth;

$\xi_{i}:$ dissipative coefficient;
$F_{\delta}(\varphi):$ sum of the dissipative forces in the mesh;

$F_{c}(\varphi)$ : sum of the elastic forces in the mesh;

$\mathrm{n}:$ number of tooth pairs in the mesh;

$\varphi$ : angle of rotation of the gear;

The results of the solution of the equations for three types of gears without errors are shown in Fig. (4) for one period of stationary vibrations and for tooth mesh frequencies from 0 to $3000 \mathrm{~Hz}$. It can be concluded from the figures that:

1) the standard gears have very high amplitudes of vibrations (Fig. 4a), 
2) the amplitudes of vibrations diminish in high contact ratio gears with standard tooth height (Fig. 4b),

3) vibrations almost completely disappear in the case of high contact ratio gear with slightly increased tooth height and contact ratio equal to 1.96 (Fig. 4c),

4) the curves at zero frequency are identical to the static transmission error curves in Fig. (2).

In this article only the case of high precision and heavy loaded spur gears was considered when the effect of tooth errors can be neglected. This is done to see the effect of high contact ratio in a pure form. Nevertheless the developed gear model allows for consideration of tooth errors which will be done in a future work.

An experiment is done to prove the theoretical results. The gears with parameters presented in table 1 (pair 1 and pair 3) are tested in a gear test rig with open contour. The teeth are cut in a gear hobbing machine to quality 8 ISO. To meet the condition of heavy loaded gear the gear width is only $5 \mathrm{~mm}$. The noise level is measured at a distance of 0.5 $\mathrm{m}$ from the gears. The noise level of high contact ratio gears are $6 \mathrm{dBA}$ less than standard gears at 1500 r.p.m.

\section{CONCLUSIONS}

1. Methods and programs are developed to calculate static and dynamic transmission errors under load in spur gears. A tooth mesh of periodic structure is used which takes into account deflection and errors of each pair of teeth in the engagement.

2. The analysis of static and dynamic transmission errors in high precision heavy loaded standard gears, high contact ratio gears of standard tooth height and high contact ratio gears with slightly increased tooth addendum showed that in the last type of gears the static and dynamic transmission errors can be almost completely excluded.

3. Preliminary experiments show that high contact ratio spur gear have noise level considerably less than standard gears.

\section{REFERENCES}

[1] R. Kasuba, "Dynamic Loads in Normal and High Contact Ratio Spur Gearing", in International Symposium on Gearing and Power Transmissions, Tokyo, pp. 49-55, 1981.

[2] T. Sato, K. Umezawa, J. Ishikawa, "Influence of Various Gear Errors on Rotational Vibration", in International Symposium on Gearing and Power Transmissions, Tokyo, pp. 55-60, 1981.

[3] A. Kahraman, G.W. Blankenship, "Effect of Involute Contact Ratio on Spur Gear Dynamics", Transactions of ASME, Journal of Mechanical Design, vol. 121, pp. 112-118, March 1999.

[4] H.H. Lin, J. Wang, F. Oswald, J.J. Coy, " Effect of Extended Tooth Contact on the Modeling of Spur Gear Transmissions", Gear Technology, pp. 18-25, July/August 1994.

[5] V.I. Nikolayev, E.I. Podzharov, "Involute Spur Gear", SU Patent 1320568, February 12, 1986.

[6] E.B. Vulgakov, Gears with Better Properties, Moscow: Mashinostroenie, 1974.

[7] W.S. Rouverol, Y. Watanabe, "Maximum-Conjugacy Gearing. Part 1. Theory", in International Symposium on Gearing and Power Transmissions, Tokyo, 1981, pp. 103-108.

[8] Y. Watanabe, W.S. Rouverol, "Maximum-Conjugacy Gearing. Part 2. Test Results", in International Symposium on Gearing and Power Transmissions, Tokyo, 1981, pp. 109-114.

[9] H. Yelle, D.J. Burns, "Calculation of Contact Ratio for Plastic / Steel Spur Gear Pairs”, Journal of Mechanical Design, vol. 103(2), pp. 168-180, 1981.

[10] E.P. Remmers, "Gear Mesh Excitation Spectra for Arbitrary Tooth Spacing Errors, Load and Design Contact Ratio", Journal of Mechanical Design, vol. 100(4), pp. 65-74, 1978.

[11] A. Seireg, A.D.R. Houser, "Evaluation of Dynamic Factor for Spur and Helical Gears", Transaction of ASME. Journal of Engineering for Industry, pp. 504-515, May 1970.

[12] C. Weber, K. Bonaschek, "Formanderung und Profilrücknahme bei Gerad- und Schragverzahnten Radern", Schriftenreihe Antriebstechnik, Braunschweig Vieweg, 1955.

(C) Podzharov et al.; Licensee Bentham Open.

This is an open access article licensed under the terms of the Creative Commons Attribution Non-Commercial License (http://creativecommons.org/ licenses/by-nc/3.0/) which permits unrestricted, non-commercial use, distribution and reproduction in any medium, provided the work is properly cited. 